CrossMark

$<$ click for updates

Cite this: Food Funct., 2017, 8, 103

Received 30th October 2016, Accepted 12th December 2016

DOI: 10.1039/c6fo01600f

www.rsc.org/foodfunction

\section{Development of dairy beverages functionalized with pure ergosterol and mycosterol extracts: an alternative to phytosterol-based beverages $\uparrow$}

\author{
Sandrina A. Heleno, ${ }^{a, b}$ Adenilson R. Rudke, ${ }^{a, b}$ Ricardo C. Calhelha, ${ }^{a}$ \\ Márcio Carocho, ${ }^{\mathrm{a}, \mathrm{b}}$ Lillian Barros, ${ }^{\mathrm{a}, \mathrm{b}}$ Odinei H. Gonçalves, ${ }^{c}$ Maria Filomena Barreiro ${ }^{\mathrm{b}}$ \\ and Isabel C. F. R. Ferreira*a
}

\begin{abstract}
In the present work, Agaricus bisporus extracts obtained by ultrasound-assisted extraction (UAE), and ergosterol, were incorporated into dairy beverages at concentrations mimicking commercial phytosteroladded yogurts, to work as alternatives. The samples were analysed for nutritional and bioactive properties, and compared with controls (yogurts with no additives or phytosterols), at two storage times (right after incorporation $(\mathrm{ST}=0)$ and after seven days at $4{ }^{\circ} \mathrm{C}(\mathrm{ST}=7)$ ). The ones incorporated with the extract $(\mathrm{YAb})$ and with ergosterol at the same concentration as in the extract (YPEAb) showed similar antioxidant properties as the ones with phytosterols (YPhy), but a higher cytotoxicity against tumor cells. YPEPhy, the sample with ergosterol at the same amount as phytosterols in YPhy, was the strongest in both bioactivities. For YAb, YPEAb and YPEPhy the antioxidant capacity increased from ST $=0$ to ST $=7$, meaning that the extract and ergosterol protected the yogurt from oxidation, improving the shelf life. Nutritional parameters were identical for all samples.
\end{abstract}

\section{Introduction}

The market for functional foods is evolving very fast, its growth estimated as being $10 \%$ per year. In this business segment, the fastest growing sector is the one of functional beverages (functional drinks) ${ }^{1}$ which grew 2.5\%, between 2008 and 2011, in Latin America. ${ }^{2}$ Also in this context, functional dairy products in Germany had an impressive increment from 5 million dollars in 1995 to over $\$ 300$ million in $2000 .^{3}$

Dairy beverages containing phytosterols, which are molecules claimed to be able to decrease cholesterol levels, ${ }^{4}$ can be currently found at the commercial level. In fact, the consumption of standardized levels of sterols is recommended by both European and US guidelines. Besides plants, these molecules also exist in macrofungi, in this case designated as mycosterols, ergosterol being the most abundant sterol in Agaricus bisporus (J. E. Lange) Imbach. ${ }^{5,6}$

\footnotetext{
${ }^{a}$ Mountain Research Centre (CIMO), ESA, Polytechnic Institute of Bragança, Portugal. E-mail: iferreira@ipb.pt; Fax: +351273325405; Tel: +351273303219

${ }^{b}$ Laboratory of Separation and Reaction Engineering - Laboratory of Catalysis and Materials (LSRE-LCM), Polytechnic Institute of Bragança, Portugal ${ }^{c}$ Post-Graduation Program of Food Technology (PPGTA), Federal University of Technology - Paraná - UTFPR, Campus Campo Mourão, Brasil

$\dagger$ Electronic supplementary information (ESI) available. See DOI: 10.1039/ c6fo01600f
}

A. bisporus is the most cultivated and consumed mushroom worldwide, with an output of 4 million tons in 2009. ${ }^{7}$ This high production and consumption can be explained not only by its pleasant taste, but also by its biological properties, such as antioxidant, ${ }^{8,9}$ antimicrobial, ${ }^{8,10}$ anti-inflammatory, ${ }^{11,12}$ and antitumor $^{13}$ properties among others. These bioactivities are related to bioactive molecules such as phenolic compounds and tocopherols, ${ }^{10,12}$ but also to ergosterol that represents approximately $90 \%$ of its sterol fraction. ${ }^{5,14,15}$ In addition, ergosterol is reported as having interesting hypocholesterolemic activity, acting like phytosterols. ${ }^{16,19}$

The mushroom industry generates large quantities of byproducts $^{17}$ whose amount can vary between 20 and $35 \%$ in weight of fresh mushrooms. ${ }^{18,19}$ These residues can proceed from cultivation and harvest, where specimens with irregular dimensions and shape are discarded, but can also include other by-products such as the volva and bottom part of the stems due to their tough texture. They usually have no valued destination, being used for low-economic solutions such as animal feed and compost. Alternatively, these by-products can be proposed to extract ergosterol thus obtaining a high added value molecule for various industrial applications (100 $\mathrm{g}$ of the product with $98 \%$ of purity can cost about $\$ 800$ ).

In the present work, mycosterol enriched extracts were prepared from A. bisporus bio residues by ultrasound-assisted extraction (UAE). These extracts, as well as pure ergosterol, were 
incorporated into dairy beverages at concentrations reproducing commercial phytosterol-added counterparts. The achieved differences and advantages were discussed aiming at highlighting the competitive role of mycosterols towards phytosterols.

\section{Materials and method}

\subsection{Samples}

Agaricus bisporus L. bio residues (volva and the bottom part of the stem, specimens with irregular dimensions) were obtained from a local mushroom production enterprise "Mogaricus Cogumelos - Sociedade Unipessoal Lda". The samples were weighed, lyophilized (FreeZone 4.5 model 7750031, Labconco, Kansas City, MO, USA) and reduced to a fine dried powder (20 mesh) for subsequent assays.

The base yogurts for the dairy beverages' preparation were purchased from a local supermarket. They were composed of partly skimmed milk, sugar, glucose-fructose syrup, lactose, milk proteins, strawberry pulp $(1.4 \%, \mathrm{w} / \mathrm{w})$, modified corn starch, flavorings, lactic ferments, a preserver (E202) and a dye (E120). The nutritional declaration per $100 \mathrm{~g}$ includes: energy: $72 \mathrm{kcal}$; lipids: $1.1 \mathrm{~g}$ corresponding to $0.7 \mathrm{~g}$ of saturated fatty acids; carbohydrates: $13 \mathrm{~g}$ corresponding to sugars; proteins: $2.3 \mathrm{~g}$ and salt: $0.13 \mathrm{~g}$. Commercial yogurts with phytosterols include in their composition light milk, esters of plant sterols $(3.4 \%, w / w)$ that correspond to $2 \%$ of free plant sterols, strawberry pulp $(2.5 \%, \mathrm{w} / \mathrm{w})$, lactose and milk proteins, modified corn starch, flavorings, lactic ferments, sweeteners (E955, E950), a preserver (E202) and a dye (E120), with the following nutritional declaration per $100 \mathrm{~g}$ : energy: $41 \mathrm{kcal}$; lipids: $1.4 \mathrm{~g}$ corresponding to $0.1 \mathrm{~g}$ of saturated fatty acids; carbohydrates: $4.2 \mathrm{~g}$ corresponding to $4.0 \mathrm{~g}$ of sugars; proteins: $3.0 \mathrm{~g}$ and salt: $0.13 \mathrm{~g}$. For energy purposes, the $2 \mathrm{~g}$ from the plant sterols were excluded since they do not contribute to the energetic value. Both yogurts had a shelf life of 21 days. The used solution, in terms of the chosen base yogurts and yogurts added with phytosterols, was the most suitable face for the existing market options. In fact, no natural yogurts incorporated with phytosterols were found, which is the reason why the strawberry flavored ones were used, to guarantee as much similarity as possible among the samples.

\subsection{Standards and reagents}

Methanol and acetonitrile of HPLC grade, and chloroform and ethanol of analytical grade were acquired from Fisher Scientific (Lisbon, Portugal). Trolox (6-hydroxy-2,5,7,8-tetramethylchroman-2-carboxylic acid), the sterol standards: ergosterol (98\%) and cholecalciferol (98\%) were purchased from Sigma (St Louis, MO, USA), as well as, as also acetic acid, phosphate buffered saline (PBS), sulforhodamine B (SRB), trypan blue, trichloroacetic acid (TCA) and tris-(hydroxymethyl)aminomethane (TRIS). Dulbecco's Modified Eagle's Medium (DMEM) and RPMI-1640 medium, fetal bovine serum (FBS), Hank's balanced salt solution (HBSS), L-glutamine, nonessential amino acid solution $(2 \mathrm{mM})$, penicillin/streptomycin solu- tion (100 $\mathrm{U} \mathrm{mL}^{-1}$ and $100 \mathrm{mg} \mathrm{mL}^{-1}$, respectively), and trypsinEDTA (ethylenediaminetetraacetic acid) were from Hyclone (Logan, UT, USA). Water was treated in a Milli-Q water purification system (TGI Pure Water Systems, Greenville, SC, USA) before use. 2,2-Diphenyl-1-picrylhydrazyl (DPPH) was obtained from Alfa Aesar (Ward Hill, MA, USA). All other chemicals and solvents were of analytical grade and purchased from common suppliers.

\subsection{Preparation of the dairy beverages}

2.3.1. Mycosterol extract production. Ultrasound-assisted extraction (UAE) was carried out using an ultrasonic device (QSonica sonicators, model CL-334, Newtown, CT, USA), comprising an ultrasound probe working in the range of 100 to $500 \mathrm{~W}$ at $20 \mathrm{kHz}$ and equipped with a digital timer. Extractions were carried out according to Heleno et al. ${ }^{20}$ Briefly, the lyophilized powdered mushroom samples ( $3 \mathrm{~g}$ ) were extracted with $100 \mathrm{~mL}$ of ethanol using previously optimized conditions ( $15 \mathrm{~min}, 375 \mathrm{w}$ ). Before each extraction, an adequate volume of cholecalciferol (internal standard) was added. After extraction, the extract solution was filtered through a Whatman no. 4 paper and the solvent evaporated under reduced pressure to obtain the mycosterol extracts.

2.3.2. Monitoring ergosterol in the mycosterol extracts. The obtained mycosterol extract was dissolved in methanol at $10 \mathrm{mg} \mathrm{mL}^{-1}$ and filtered through a $0.2 \mu \mathrm{m}$ nylon filter for ergosterol quantification by HPLC-UV analysis. Ergosterol quantification was carried out according to Barreira et al. ${ }^{5}$ using an HPLC equipment coupled with an UV detector. The equipment consisted of an integrated system with a pump (Knauer, Smartline system 1000, Berlin, Germany), a degasser system (Smartline manager 5000), an auto-sampler (AS-2057 Jasco, Easton, MD) and a UV detector (Knauer Smartline 2500). Chromatographic separation was achieved with a Inertsil 100A ODS-3 reversed-phase column $(4.6 \times 150 \mathrm{~mm}, 5 \mu \mathrm{m}, \mathrm{BGB}$ Analytik AG, Boeckten, Switzerland) operating at $35{ }^{\circ} \mathrm{C}(7971 \mathrm{R}$ Grace oven). The mobile phase was acetonitrile/methanol $(70: 30, \mathrm{v} / \mathrm{v})$ at a flow rate of $1 \mathrm{~mL} \mathrm{~min}^{-1}$, the injection volume was $20 \mu \mathrm{L}$ and the detection was performed at $280 \mathrm{~nm}$. Ergosterol was quantified based on a calibration curve obtained from a commercial standard using the internal standard method with cholecalciferol as the internal standard. Data were analyzed using Clarity 2.4 Software (DataApex).

2.3.3. Incorporation of dairy beverages with mycosterol extracts or pure ergosterol. The dairy beverages (100 g each) were prepared as follows: FY (base yogurt with no additives), YPhy (commercial yogurt containing phytosterols (2 g)), YAb (yogurt incorporated with $2 \mathrm{~g}$ of A. bisporus mycosterol solid extract, i.e. mimicking the used quantity of phytosterols in commercial yogurts), YPEAb (yogurt incorporated with $75 \mathrm{mg}$ of pure ergosterol, i.e. representing the ergosterol amount present in the $2 \mathrm{~g}$ of the mycosterol extract) and YPEPhy (yogurt incorporated with $2 \mathrm{~g}$ of pure ergosterol, i.e. mimicking the used quantity of phytosterols in commercial yogurts). The samples FY and YPhy were used as control samples. Yogurts were prepared in duplicate and further analyzed at two 
different Storage Times (ST): immediately after production $(\mathrm{ST}=0)$, and after 7 days of storage at $4{ }^{\circ} \mathrm{C}(\mathrm{ST}=7)$. All samples were lyophilized before analysis.

\subsection{Nutritional value of the developed dairy beverages}

2.4.1. Macronutrients and energetic value. Moisture, proteins, fat, carbohydrates and ash were determined using the AOAC procedures ${ }^{21}$ and according to the procedures described by Souza et $a .^{22}$ Energy was calculated using eqn (1) (mass in grams) according to the European Parliament and Council Regulation No. 1169.

$$
\operatorname{Energy}(\mathrm{kcal})=4\left(m_{\text {protein }}+m_{\text {carbohydrate }}\right)+9 g_{\text {fat }}
$$

2.4.2. Soluble sugars. Soluble sugars were determined by High Performance Liquid Chromatography (HPLC, Knauer, Smartline system 1000) coupled with a refractive index detector (RI detector, Knauer Smartline 2300) according to the procedures of Heleno et al. ${ }^{23}$ and Souza et al. ${ }^{22}$ Quantification was based on calibration curves obtained for individual sugars by the internal standard method (IS, raffinose). Data were analyzed using Clarity 2.4 Software (DataApex). Results were expressed in $\mathrm{g}$ per $100 \mathrm{~g}$ of dry weight.

2.4.3. Fatty acids. Fatty acids were determined after transesterification according to the procedure described previously by the authors Heleno et $a ._{.}{ }^{23}$ and Souza et $a .^{22}$ by gas chromatography (DANI 1000) with a flame ionization detector (GC-FID). Fatty acid identification was done by comparison with the relative retention times of FAME (Fatty Acid Methyl Esters) peaks obtained from standards. Results were recorded and processed using CSW 1.7 software (DataApex 1.7) and expressed in relative percentages of each fatty acid.

\subsection{Bioactive properties of the developed dairy beverages}

2.5.1. DPPH radical scavenging activity. The mycosterol extract was dissolved in methanol at $50 \mathrm{mg} \mathrm{mL} \mathrm{m}^{-1}$; ergosterol was dissolved in chloroform at $1 \mathrm{mg} \mathrm{mL}^{-1}$; and yogurt was dissolved in a mixture of methanol: chloroform $(50: 50, \mathrm{v} / \mathrm{v})$ at $200 \mathrm{mg} \mathrm{mL} \mathrm{m}^{-1}$. Successive dilutions were thereafter prepared from these stock solutions.

The used methodology was carried out according to Heleno et $a .^{24}$ The reaction mixture consisted of the sample solutions with different concentrations $(30 \mu \mathrm{L})$ and a methanolic solution $(270 \mu \mathrm{L})$ containing DPPH radicals $\left(6 \times 10^{-5} \mathrm{~mol} \mathrm{~L}^{-1}\right)$. The mixture was left to stand for $30 \mathrm{~min}$ in the dark, and the absorption was measured at $515 \mathrm{~nm}$ (ELX800 Microplate Reader, Bio-Tek, Winooski, VT, USA). The radical scavenging activity (RSA) was calculated as a percentage of DPPH discoloration using eqn (2), where AS is the absorbance of the solution containing the sample, and ADPPH is the absorbance of the DPPH solution. Trolox was used as a positive control.

$$
\mathrm{RSA}(\%)=\frac{[(\mathrm{ADPPH}-\mathrm{AS})}{\mathrm{ADPPH}} \times 100
$$

2.5.2. Cytotoxic properties. The mycosterol extract was dissolved in water at $8 \mathrm{mg} \mathrm{mL}^{-1}$; ergosterol was dissolved in
DMSO at $40 \mathrm{mM}$; and yogurt was dissolved in $\mathrm{DMSO} /$ water $(1: 1)$ at $8 \mathrm{mg} \mathrm{mL} \mathrm{m}^{-1}$. Successive dilutions were thereafter prepared from these stock solutions.

MCF-7 (breast adenocarcinoma), NCI-H460 (non-small cell lung carcinoma), HeLa (cervical carcinoma) and HepG2 (hepatocellular carcinoma) from DSMZ (Leibniz-Institut DSMZ-Deutsche Sammlung von Mikroorganismen und Zellkulturen $\mathrm{GmbH}$ ) were used as human tumor cell lines. To assess the cytotoxicity of the samples, the sulforhodamine B assay was performed according to a procedure previously described by the authors Abreu et al. ${ }^{25}$

For toxicity evaluation toward liver cells, a primary cell culture was prepared according to a procedure previously established by Abreu et al. ${ }^{25}$ These cells (PLP2) were treated for $48 \mathrm{~h}$ with the different sample solutions and the SRB assay was followed. $^{22}$

The results were expressed in $\mathrm{GI}_{50}$ values (concentrations that inhibited $50 \%$ of the net cell growth). Ellipticine was used as a positive control.

\subsection{Statistical analysis}

The incorporations were performed in duplicate and all analyses were carried out in triplicate. Throughout the manuscript, all data are expressed as the mean \pm standard deviation or mean \pm amplitude, when stated. In order to allow a better interpretation of the results, analyses of variance (ANOVA) with type III sums of squares were performed using the SPSS software, version 23. Relying on a multivariate general linear model, the dependent variables were analyzed though a 2-way ANOVA with 2 independent variables. Storage Time (ST) comprised the values 0 and 7 days, and Incorporation Type (IT) comprised FY, YPhy, YAb, YPEAb and YPEPhy, and their meanings are previously described in section 2.3.3. When, in each assay, a significant interaction was detected for both factors $(\mathrm{ST} \times \mathrm{IT})$ meaning that the changes among the samples were influenced by both factors, they were evaluated simultaneously, and general tendencies were drawn from the Estimated Marginal Means (EMM). Inversely, if no statistical interaction was detected, the means were compared by a Student's $T$ test (for ST) or a Tukey's multiple comparison test (for IT), relying on a previous Levene's test for the equality of variances. All tests were performed at a 5\% significance level.

\section{Results and discussion}

In order to determine the viability of using A. bisporus as a source of mycosterols to be used as functional additives in food products, a detailed analysis of the developed dairy beverages was carried out in terms of the nutritional profile, soluble sugars, fatty acids, antioxidant and cytotoxic activities. In all the tables, ST is presented as a mean accounting with all incorporation types, and IT as a mean accounting with both storage times. With this approach, the contribution of each factor, ST and IT, can be interpreted independently. Thus, the amplitude reflects values obtained under different conditions 
Table 1 Ergosterol content in the samples after incorporation

\begin{tabular}{lll}
\hline Ergosterol content $(\mathrm{g}$ per $100 \mathrm{~g})$ & \\
\hline $\mathrm{ST}$ & 0 days & 7 days \\
\hline $\mathrm{FY}$ & $\mathrm{Nd}$ & $\mathrm{Nd}$ \\
YPhy & $\mathrm{Nd}$ & $\mathrm{Nd}$ \\
YAb & $0.061 \pm 0.01$ & $0.062 \pm 0.01$ \\
YPEAb & $0.062 \pm 0.01$ & $0.063 \pm 0.01$ \\
YPEPhy & $1.952 \pm 0.03$ & $1.968 \pm 0.02$
\end{tabular}

Ergosterol content in the Agaricus bisporus extract: $36.72 \pm 0.01 \mathrm{mg} \mathrm{g}^{-1}$ extract; nd - not detected.

(variations of the non-fixed factor: ST or IT). If a significant interaction was detected between both factors ( $\mathrm{ST} \times \mathrm{IT}<0.05)$, no multiple comparisons could be performed, meaning that both factors contributed to the observed changes in the results, so no specific conclusions can be drawn, and therefore, general conclusions were obtained from the estimated marginal means (EMM). The A. bisporus content in ergosterol is shown in Table 1 as the $36.72 \pm 0.01 \mathrm{mg} \mathrm{g}^{-1}$ extract, in agreement with previous reports that described this mushroom as the richest one in ergosterol..$^{5,20}$

\subsection{Evaluation of the ergosterol content in the prepared dairy beverages}

All the yogurts incorporated with the A. bisporus extract, as well as with pure ergosterol, were evaluated in terms of ergosterol content by HPLC-UV to confirm its presence right after preparation $(\mathrm{ST}=0)$ and after seven days $(\mathrm{ST}=7)$. As it can be seen from Table 1, the incorporated amounts were confirmed in the respective samples, with proximate values for $\mathrm{ST}=0$ and $\mathrm{ST}=$ 7 , meaning that ergosterol remains stable in the analyzed food matrix (yogurt) after seven days under storage at $4{ }^{\circ} \mathrm{C}$.

\subsection{Analysis of nutritional profile and energy}

Table 2 represents the nutritional profile and energy values for the evaluated yogurt samples. Moisture was the parameter with the highest value, as expected for yogurts. Nutritionally, total carbohydrates followed by proteins were the most abundant macronutrients. The nutritional profile, in terms of fatty acids and soluble sugars, achieved for the yogurts with phytosterols (YPhy) differed from the other ones, which can be justified due to the use of a different brand. For instance, this sample had less carbohydrates and lower energy. For all the performed assays, the interaction between factors ST and IT was significant, so general conclusions were drawn from the EMM. In terms of the moisture content, IT had a higher influence than ST, although no significant differences could be achieved. Based on the EMM, the yogurts incorporated with the A. bisporus extract (YAb), and the commercial ones enriched with phytosterols (YPhy), showed fat preservation over the storage time, which indicates the antioxidant activity of this mushroom extract (ESI $1 \mathrm{~A} \dagger$ ), similar to the one of phytosterols. Furthermore, A. bisporus seemed to have preserved the protein fraction (data not shown), which is quite desirable, given that protein destruction in foodstuffs is usually related to off flavors. Overall, the nutritional profile of the yogurts was not significantly modified by any type of incorporation, and given that the yogurts were kept at an adequate storage temperature, few changes were actually expected for the studied storage period (7 days).

\subsection{Effects on soluble sugars}

Generally speaking, six soluble sugars were detected in the studied samples, namely glucose, fructose, sucrose, lactose, galactose and mannitol (Table 3). Mannitol was only detected in the yogurts added with the A. bisporus extract, although it co-eluted with galactose. The most abundant soluble sugar was sucrose, followed by lactose. For the sample containing phytosterols (YPhy), no fructose was detected and lower amounts of sucrose and lactose were detected. For all sugars but galactose, there was a significant interaction between ST and IT. For this soluble sugar, all samples were significantly different. The highest amount was recorded in the yogurt with the A. bisporus extract (YAb) and the lowest in the yogurt with pure ergosterol at an amount mimicking the one present in the A. bisporus extract (YPEAb). Overall, there was an increase of lactose overtime, which can be explained by the combination of galactose with glucose, the monosaccharides of this disaccharide. Through the EMM, it can be concluded that only the control samples (FY - base yogurt with no additives)

Table 2 Nutritional profile (g per $100 \mathrm{~g}$ ) and energy values (kcal per $100 \mathrm{~g}$ ) of the evaluated yogurt samples

\begin{tabular}{|c|c|c|c|c|c|c|c|}
\hline & & Moisture & Fat & Protein & Ash & Total carbohydrates & Energy \\
\hline \multirow[t]{2}{*}{ Storage time (ST) } & 0 days & $81 \pm 3$ & $1.5 \pm 0.4$ & $4.1 \pm 0.4$ & $1.19 \pm 0.04$ & $12 \pm 3$ & $329 \pm 41$ \\
\hline & 7 days & $81 \pm 3$ & $1.6 \pm 0.5$ & $3.9 \pm 0.3$ & $1.1 \pm 0.1$ & $12 \pm 4$ & $333 \pm 45$ \\
\hline$p$-Value $(n=30)$ & Student $T$ test & 0.44 & 0.003 & $<0.001$ & $<0.001$ & $<0.001$ & $<0.001$ \\
\hline \multirow{5}{*}{ Incorporation type (IT) } & $\mathrm{FY}$ & $80.0 \pm 0.1$ & $0.99 \pm 0.02$ & $3.75 \pm 0.03$ & $1.19 \pm 0.03$ & $14.0 \pm 0.1$ & $335 \pm 2$ \\
\hline & YPhy & $86.7 \pm 3$ & $2.3 \pm 0.2$ & $4.11 \pm 0.05$ & $1.1 \pm 0.1$ & $5.7 \pm 0.3$ & $251 \pm 1$ \\
\hline & YPEAb & $80.2 \pm 0.7$ & $1.41 \pm 0.05$ & $4.2 \pm 0.6$ & $1.13 \pm 0.04$ & $13.07 \pm 0.9$ & $342 \pm 11$ \\
\hline & YPEPhy & $79.3 \pm 0.9$ & $1.5 \pm 0.2$ & $3.6 \pm 0.1$ & $1.10 \pm 0.06$ & $14.4 \pm 0.9$ & $361 \pm 17$ \\
\hline & $\mathrm{YAb}$ & $78.7 \pm 0.1$ & $1.46 \pm 0.06$ & $4.2 \pm 0.2$ & $1.19 \pm 0.05$ & $14.4 \pm 0.3$ & $367 \pm 4$ \\
\hline$p$-Value $(n=12)$ & Tukey's HSD test & $<0.001$ & $<0.001$ & $<0.001$ & $<0.001$ & $<0.001$ & $<0.001$ \\
\hline $\mathrm{ST} \times \operatorname{IT}(n=60)$ & $p$-Value & $<0.001$ & $<0.001$ & $<0.001$ & $<0.001$ & $<0.001$ & $<0.001$ \\
\hline
\end{tabular}

Results are expressed as mean \pm amplitude (values obtained under different conditions - variations of the non-fixed factor: ST or IT). 
Table 3 Soluble sugar (g per $100 \mathrm{~g}^{-1}$ ) composition of the evaluated yogurt samples

\begin{tabular}{|c|c|c|c|c|c|c|c|}
\hline & & Fructose & Glucose & Sucrose & Lactose & Galactose & Total sugars \\
\hline \multirow[t]{2}{*}{ Storage time (ST) } & 0 days & $0.3 \pm 0.1$ & $0.97 \pm 0.06$ & $4 \pm 2$ & $2 \pm 1$ & $0.6 \pm 0.4$ & $8 \pm 3$ \\
\hline & 7 days & $0.15 \pm 0.09$ & $0.98 \pm 0.07$ & $5 \pm 3$ & $3 \pm 2$ & $0.5 \pm 0.4$ & $10 \pm 4$ \\
\hline$p$-Value $(n=30)$ & Student $T$ test & $<0.001$ & 0.241 & $<0.001$ & $<0.001$ & 0.03 & $<0.001$ \\
\hline \multirow[t]{5}{*}{ Incorporation type (IT) } & FY & $0.31 \pm 0.02$ & $1.00 \pm 0.01$ & $4.5 \pm 0.3$ & $3.5 \pm 0.6$ & $0.23 \pm 0.06^{\mathrm{b}}$ & $9.5 \pm 0.2$ \\
\hline & YPhy & - & $0.90 \pm 0.02$ & $0.031 \pm 0.002$ & $0.099 \pm 0.002$ & $1.02 \pm 0.02^{\mathrm{d}}$ & $2.05 \pm 0.05$ \\
\hline & YPEAb & $0.2 \pm 0.1$ & $0.97 \pm 0.05$ & $6 \pm 1$ & $3.8 \pm 0.8$ & $0.15 \pm 0.04^{\mathrm{a}, \mathrm{b}}$ & $11 \pm 2$ \\
\hline & YPEPhy & $0.25 \pm 0.09$ & $1.00 \pm 0.08$ & $6 \pm 1$ & $3.7 \pm 0.7$ & $0.24 \pm 0.02^{c, b}$ & $11 \pm 2$ \\
\hline & $\mathrm{YAb}$ & $0.24 \pm 0.07$ & $1.02 \pm 0.05$ & $6.0 \pm 0.6$ & $3.8 \pm 0.6$ & $a_{1.1} \pm 0.3^{\mathrm{e}}$ & $12 \pm 1$ \\
\hline$p$-Value $(n=12)$ & Tukey's HSD test & $<0.001$ & $<0.001$ & $<0.001$ & $<0.001$ & $<0.001$ & $<0.001$ \\
\hline $\mathrm{ST} \times \operatorname{IT}(n=60)$ & $p$-Value & $<0.001$ & $<0.001$ & $<0.001$ & $<0.001$ & 0.346 & $<0.001$ \\
\hline
\end{tabular}

Results are expressed as mean \pm amplitude (values obtained under different conditions - variations of the non-fixed factor: ST or IT). ${ }^{a}$ Galactose + mannitol.

Table 4 Fatty acid composition (relative percentage) of the evaluated yogurt samples

\begin{tabular}{|c|c|c|c|c|c|c|c|c|c|c|}
\hline & & C14:0 & C16:0 & C18:0 & C18:1 & C18:2 & C18:3 & SFA & MUFA & PUFA \\
\hline \multirow[t]{2}{*}{ Storage time (ST) } & 0 days & $8 \pm 4$ & $24 \pm 9$ & $9 \pm 4$ & $28 \pm 12$ & $10 \pm 6$ & $2 \pm 4$ & $58 \pm 23$ & $30 \pm 12$ & $12 \pm 10$ \\
\hline & 7 days & $9 \pm 4$ & $24 \pm 9$ & $9 \pm 4$ & $27 \pm 13$ & $10 \pm 6$ & $2 \pm 4$ & $58 \pm 23$ & $29 \pm 13$ & $13 \pm 10$ \\
\hline$p$-Value $(n=30)$ & Student $T$ test & $<0.001$ & $<0.001$ & 0.001 & $<0.001$ & $<0.001$ & $<0.001$ & 0.006 & $<0.001$ & $<0.001$ \\
\hline Incorporation & FY & $10.2 \pm 0.1$ & $28.9 \pm 0.4$ & $12.7 \pm 0.1$ & $20.8 \pm 0.2$ & $7.1 \pm 0.2$ & $0.35 \pm 0.02$ & $69.6 \pm 0.3$ & $22.9 \pm 0.4$ & $7.4 \pm 0.2$ \\
\hline \multirow[t]{4}{*}{ type (IT) } & YPhy & $0.79 \pm 0.1$ & $6.27 \pm 0.05$ & $2.1 \pm 0.1$ & $52.8 \pm 0.5$ & $21.43 \pm 0.06$ & $11.30 \pm 0.05$ & $12.9 \pm 0.4$ & $54.3 \pm 0.4$ & $32.80 \pm 0.05$ \\
\hline & YPEAb & $10.68 \pm 0.08$ & $27.8 \pm 0.3$ & $10.9 \pm 0.4$ & $21.1 \pm 0.6$ & $7.0 \pm 0.4$ & $0.30 \pm 0.08$ & $69.2 \pm 0.3$ & $23.1 \pm 0.6$ & $7.3 \pm 0.5$ \\
\hline & YPEPhy & $10.8 \pm 0.7$ & $28.8 \pm 0.6$ & $11.0 \pm 0.4$ & $21.4 \pm 0.6$ & $7.53 \pm 0.07$ & $0.31 \pm 0.03$ & $68.7 \pm 0.5$ & $23.4 \pm 0.6$ & $7.8 \pm 0.1$ \\
\hline & $\mathrm{YAb}$ & $10.8 \pm 0.5$ & $28.3 \pm 0.4$ & $10.4 \pm 0.3$ & $21.2 \pm 0.5$ & $7.2 \pm 0.4$ & $0.38 \pm 0.03$ & $68.5 \pm 0.8$ & $23.2 \pm 0.4$ & $7.6 \pm 0.4$ \\
\hline$p$-Value $(n=12)$ & $\begin{array}{l}\text { Tukey's HSD } \\
\text { test }\end{array}$ & $<0.001$ & $<0.001$ & $<0.001$ & $<0.001$ & $<0.001$ & $<0.001$ & $<0.001$ & $<0.001$ & $<0.001$ \\
\hline $\mathrm{ST} \times \mathrm{AD}(n=60)$ & $p$-Value & $<0.001$ & $<0.001$ & $<0.001$ & $<0.001$ & $<0.001$ & $<0.001$ & $<0.001$ & $<0.001$ & $<0.001$ \\
\hline
\end{tabular}

The results are expressed as mean \pm amplitude (values obtained under different conditions - variations of the non-fixed factor: ST or IT). Myristic acid (C14:0); palmitic acid (C16:0); stearic acid (C18:0); oleic acid (C18:1n9); linoleic acid (C18:2n6c); $\alpha$-linolenic acid (C18:3n3). The difference to $100 \%$ corresponds to other 11 less abundant fatty acids in the case of FY, YAb, YPEAb and YPEPhy samples and to other 15 less abundant fatty acids in the case of the YPhy sample (data not shown).

showed a decrease in sucrose over time, while the commercial samples incorporated with phytosterols (YPhy) maintained the quantities, which were very low in comparison with the other yogurt samples (ESI 1B†).

\subsection{Effects on fatty acids}

The fatty acid profiles, analyzed through GC coupled with a flame ionization detector and expressed in a relative percentage, are present in Table 4.

Only the six most abundant fatty acids are represented in the table, given their higher contribution to the nutritional and organoleptic profiles. Of these, the most abundant were oleic acid (C18:1) and palmitic acid (C16:0). Although yogurts are considered healthy foodstuffs, the saturated fatty acid (SFA) fraction was higher than the monounsaturated fraction, which in turn is higher than the polyunsaturated one; still, the most abundant individual fatty acid is oleic acid, which is known for its beneficial properties for health. ${ }^{26,27}$ The sample containing phytosterols showed a lower SFA content and a higher level of oleic and linoleic acids (C18:2). For all fatty acids, the interaction between ST and IT was significant. In fact very few changes were expected given that the yogurts had conservatives in their composition (E202, potassium sorbate), and were only kept for 7 days under refrigeration, not allowing lipid peroxidation to excerpt great effects, which could reveal the benefits of the molecules included in the A. bisporus extract.

\subsection{Effects on antioxidant activity}

The results of the antioxidant activity of $A$. bisporus and pure ergosterol are presented in Table 5. The antioxidant activity of the different yogurts relying on the 2,2-diphenyl-1-picrylhydrazyl (DPPH) radical scavenging activity is also represented in Table 5.

Both revealed antioxidant effects $\left(\mathrm{EC}_{50}\right.$ values of $3.99 \pm$ $0.04 \mathrm{mg} \mathrm{mL} \mathrm{mL}^{-1}$ and $0.46 \pm 0.01 \mathrm{mg} \mathrm{mL}^{-1}$, respectively for A. bisporus and pure ergosterol), the strong activity exhibited by ergosterol being highlighted. There was a significant interaction between the ST and IT. The best yogurt in terms of antioxidant activity was the one incorporated with pure ergosterol at the same amount as the phytosterols (YPEPhy), whilst the second one was the one incorporated with the A. bisporus extract (YAb). Summarizing, YPEPhy showed the highest activity needing $52 \pm 9 \mathrm{mg} \mathrm{mL}^{-1}$ to exert $50 \%$ of activity, followed by $\mathrm{YAb}\left(\mathrm{EC}_{50}\right.$ of $\left.93 \pm 3 \mathrm{mg} \mathrm{mL}{ }^{-1}\right)$. Although YAb and YPEAb have the same amount of ergosterol, YAb revealed a higher antioxidant activity, which can be justified due to the presence of other bioactive molecules in the extract able to 
Table 5 DPPH radical scavenging activity of the evaluated yogurt samples

\begin{tabular}{lll}
\hline & $\mathrm{EC}_{50}$ values $\left(\mathrm{mg} \mathrm{mL}^{-1}\right)$ \\
\hline Storage time (ST) & 0 days & $152 \pm 87$ \\
& 7 days & $143 \pm 104$ \\
$p$-Value $(n=30)$ & Tukey's HSD test & $<0.001$ \\
Incorporation type (IT) & FY & $324 \pm 17$ \\
& YPhy & $141 \pm 9$ \\
& YPEAb & $126 \pm 16$ \\
& YPEPhy & $52 \pm 9$ \\
& YAb & $93 \pm 3$ \\
$p$-Value $(n=12)$ & Tukey's HSD test & $<0.001$ \\
ST $\times$ IT $(n=60)$ & $p$-Value & $<0.001$ \\
& & $3.99 \pm 0.04$ \\
A. bisporus mycosterol extract & & $0.46 \pm 0.01$ \\
Pure ergosterol & & $0.041 \pm 0.001$ \\
Trolox (positive control) & &
\end{tabular}

The results for yogurt samples are expressed as mean \pm amplitude (values obtained under different conditions - variations of the nonfixed factor: ST or IT); the results for the mycosterol extract, pure ergosterol and trolox are expressed as mean \pm standard deviation.

influence the antioxidant activity. The sample providing the weakest activity was, as expected, FY (base yogurt with no additives) $\left(\mathrm{EC}_{50}=324 \pm 17 \mathrm{mg} \mathrm{mL}{ }^{-1}\right)$. Through the EMM analysis it was noticed that all samples, except the control yogurts, increased their antioxidant activity $\left(\mathrm{EC}_{50}\right.$ values became lower) (ESI 1C $\dagger$ ). This can be justified taking into account the presence of some resilient antioxidant compounds that withstand the storage time and display their activity only after a certain period of time, or by synergies among compounds. The maintenance of nutritional and organoleptic properties of foodstuff is a quite interesting result, given that these compounds offer the possibility to halt protein degradation, while conferring bioactive properties, even after 7 days of storage time. As mentioned above the ergosterol levels were maintained during this period, and the antioxidant activity increased, a fact that can be associated with ergosterol presence in the yogurts.

\subsection{Effects on cytotoxic properties}

A. bisporus and pure ergosterol results regarding the cytotoxic properties are described in Table 6. As can be seen, both A. bisporus and pure ergosterol exhibited cytotoxic effects against all the tested tumor cell lines. Furthermore, A. bisporus did not show any toxicity against the normal cells PLP2 at the maximum tested concentration. Pure ergosterol revealed toxicity at a concentration of $89.54 \pm 3.29 \mu \mathrm{g} \mathrm{mL} \mathrm{m}^{-1}$, which is much higher than the one needed to exert $50 \%$ of activity in tumor cells, and more importantly, much higher than the toxic concentration of the ellipticine. Table 6 also displays the cytotoxic properties of the yogurts incorporating pure ergosterol and the mushroom extract, against various human tumor cell lines (MCF-7 - breast carcinoma, NCI-H460 non-small lung carcinoma, HeLa - cervical carcinoma, HepG2 - liver carcinoma) and a non-tumor cell line from a porcine liver. This activity is generally carried out against specific individual anticancer molecules such as ellipticine (used here as the positive control) whose concentration at which $50 \%$ of the cell growth is inhibited ( $\mathrm{GI}_{50}$ values), is also registered in Table 6. Although no strong in vitro antitumor activity was expected from the samples, the objective of this assay was to determine potential chemopreventive effects of the yogurts. The achieved results pointed out the existence of a significant interaction for all tumor cell lines. The yogurt added with pure ergosterol at the same amount as the phytosterols used in commercial yogurts (YPEPhy), showed the best results. In terms of toxicity for normal cells, only this yogurt showed toxic effects at a concentration of approximately $189 \pm 8 \mu \mathrm{g} \mathrm{mL} \mathrm{m}^{-1}$. Nevertheless, this concentration is much higher than the concentration needed to exert $50 \%$ of activity against tumor cell lines. None of the other yogurts showed toxicity against PLP2 up to the maximum tested concentration $\left(400 \mu \mathrm{g} \mathrm{mL}{ }^{-1}\right)$. Thus, the toxicity observed for the non-tumor cells may be related to the used high ergosterol concentration ( $2 \mathrm{~g}$ per $100 \mathrm{~g}$ yogurt). When the ergosterol concentration is lower, as is the case of

Table 6 Cytotoxic properties of the studied yogurt samples $\left(\mathrm{Gl}_{50}\right.$ values, $\mu \mathrm{g} \mathrm{mL}^{-1}$ )

\begin{tabular}{|c|c|c|c|c|c|c|}
\hline Storage time (ST) & 7 days & $171 \pm 111$ & $147 \pm 90$ & $143 \pm 90$ & $193 \pm 120$ & $327 \pm 106$ \\
\hline \multirow[t]{3}{*}{ Incorporation type (IT) } & YPEAb & $265 \pm 27$ & $219 \pm 38$ & $217 \pm 18$ & $247 \pm 22$ & 400 \\
\hline & YPEPhy & $31 \pm 12$ & $33 \pm 7$ & $23 \pm 3$ & $41 \pm 4$ & $189 \pm 8$ \\
\hline & $\mathrm{YAb}$ & $301 \pm 49$ & $253 \pm 25$ & $261 \pm 53$ & $329 \pm 15$ & 400 \\
\hline$p$-Value $(n=12)$ & Tukey's HSD test & $<0.001$ & $<0.001$ & $<0.001$ & $<0.001$ & $<0.001$ \\
\hline & & MCF-7 & NCI-H460 & HeLa & HepG2 & PLP2 \\
\hline \multicolumn{2}{|l|}{ FY } & $>400$ & $>400$ & $>400$ & $>400$ & $>400$ \\
\hline \multicolumn{2}{|c|}{ YPhy } & $>400$ & $>400$ & $>400$ & $>400$ & $>400$ \\
\hline \multicolumn{2}{|c|}{ A. bisporus mycosterol extract } & $84 \pm 5$ & $123 \pm 9$ & $97.0 \pm 0.4$ & $95 \pm 2$ & $>400$ \\
\hline \multicolumn{2}{|c|}{ Pure ergosterol } & $30 \pm 2$ & $49 \pm 4$ & $38 \pm 2$ & $34 \pm 3$ & $89.54 \pm 3.29$ \\
\hline
\end{tabular}

The results for yogurt samples are expressed as mean \pm amplitude (values obtained under different conditions - variations of the non-fixed factor: ST or IT); the results for the mycosterol extract, pure ergosterol and ellipticine are expressed as mean \pm standard deviation. 
YAb and YPEPhy (0.075 g ergosterol per $100 \mathrm{~g}$ yogurt), no hepatotoxicity was registered. Thus, the choice of concentrations close to this late value can provide toxicity to tumor cells but not normal liver cells.

\section{Conclusion}

Bio-residues from $A$. bisporus, the most consumed mushroom worldwide, were used as a source of mycosterols to be tested in comparison to the already commercially available yogurts containing phytosterols. They can be obtained from less noble biomass provided by mushroom cultivation and processing industries, returning added value products, in-line with the circular bioeconomy concept. The used extraction procedure is simple to apply, low-cost and avoids purification steps, providing functional ingredients suitable for food and/or beverage applications, with the advantage of imparting hypocholesterolemic effects as demonstrated by Gil-Ramírez et al. ${ }^{19}$ From the obtained results, the A. bisporus extract seemed to preserve yogurt's protein and lipid fractions, probably due to its antioxidant potential. Furthermore, sucrose degradation over time also decreased and a lower toxic effect against normal cells was observed in comparison with pure ergosterol (although none of them is toxic). The yogurts incorporated with $2 \mathrm{~g}$ of the A. bisporus extract (YAb) showed a stronger bioactivity than the samples incorporated with phytosterols, meaning that this extract presents high potential for application in the food industry. In terms of the present proposal of using mycosterols, their efficacy was found very similar to phytosterols, highlighting their viable use, and benefits associated with mushroom-derived sterols, their price and availability. The fact that this extract is a mixture of molecules was found interesting since the developed synergies evidenced beneficial effects over the ascribed bioactivities. This topic is worth further investigation to uncover the potentialities of this mushroom for food applications.

\section{Conflict of interest}

There are no conflicts of interest to declare.

\section{Acknowledgements}

The authors acknowledge FCT (Portugal) for financial support to (UID/AGR/00690/2013), Sandrina A. Heleno (SFRH/BPD/101413/ 2014), L. Barros (SFRH/BPD/107855/2015) and R.C. Calhelha (SFRH/BPD/BPD/68344/2010); POCI-01-0145-FEDER-006984 (LA LSRE-LCM), funded by FEDER, through POCI-COMPETE2020 and FCT; Project NORTE-01-0145-FEDER-000006.

\section{References}

1 M. R. Corbo, A. Bevilacqua, L. Petruzzi, F. P. Casanova and M. Sinigaglia, Functional Beverages: The Emerging Side of
Functional Foods, Compr. Rev. Food Sci. Food Saf., 2014, 13, 1192-1206.

2 E. A. Pires, M. A. Ferreira, R. B. Vieira, C. A. Barbosa and F. L. Santos, Perfil dos documentos de patente referentes a tecnologias e produtos probióticos, prebióticos e simbióticos na América Latina, Cad. Prospecção, 2015, 8, 142-149.

3 I. Siró, E. Kápolna, B. Kápolna and A. Lugasi, Functional food. Product development, marketing and consumer acceptance - A review, Appetite, 2008, 51, 456-467.

4 M. P. Raju, D. G. A. Babu, B. R. Kumar and C. H. Rajashekar, The Role of Phytosterols Enriched FoodsA Review, IOSR J. Environ. Sci., Toxicol. Food Technol., 2013, 7, 40-47.

5 J. C. M. Barreira, M. B. P. P. Oliveira and I. C. F. R. Ferreira, Development of a Novel Methodology for the Analysis of Ergosterol in Mushrooms, Food Anal. Methods, 2014, 7, 217-223.

6 J. C. M. Barreira and I. C. F. R. Ferreira, Steroids in natural matrices: Chemical features and bioactive properties, in Biotechnology of Bioactive Compounds, John Wiley \& Sons, Ltd, Chichester, UK, 2015, pp. 395-431.

7 F. J. Leiva, J. C. Saenz-Díez, E. Martínez, E. Jiménez and J. Blanco, Environmental impact of Agaricus bisporus mycelium production, Agric. Syst., 2015, 138, 38-45.

8 M. Öztürk, M. E. Duru, S. Kivrak, N. M. Dogan, A. Türkoglu and M. A. Özler, In vitro antioxidant, anticholinesterase and antimicrobial activity studies on three Agaricus species with fatty acid compositions and iron contents: A comparative study on the three most edible mushrooms, Food Chem. Toxicol., 2011, 49, 1353-1360.

9 J. Liu, L. Jia, J. Kan and C. Jin, In vitro and in vivo antioxidant activity of ethanolic extract of white button mushroom (Agaricus bisporus), Food Chem. Toxicol., 2013, 51, 310-316.

10 L. Barros, T. Cruz, P. Baptista, L. M. Estevinho and I. C. F. R. Ferreira, Wild and commercial mushrooms as source of nutrients and nutraceuticals, Food Chem. Toxicol., 2008, 46, 2742-2747.

11 A. C. Ruthes, Y. D. Rattmann, S. M. Malquevicz-Paiva, E. R. Carbonero, M. M. Córdova, C. H. Baggio, A. R. S. Santos, P. A. J. Gorin and M. Iacomini, Agaricus bisporus fucogalactan: structural characterization and pharmacological approaches, Carbohydr. Polym., 2013, 92, 184-191.

12 O. Taofiq, R. C. Calhelha, S. Heleno, L. Barros, A. Martins, C. Santos-Buelga, M. J. R. P. Queiroz and I. C. F. R. Ferreira, The contribution of phenolic acids to the anti-inflammatory activity of mushrooms: Screening in phenolic extracts, individual parent molecules and synthesized glucuronated and methylated derivatives, Food Res. Int., 2015, 76, 821-827.

13 M. S. Ahmad, S. Ahmad, B. Gautam and M. Afzal, Antigenotoxic and anticlastogenic potential of Agaricus bisporus against MMS induced toxicity in human lymphocyte cultures and in bone marrow cells of mice, Egypt J. Med. Hum. Genet., 2013, 14, 395-402. 
14 S. Shao, M. Hernandez, J. K. G. Kramer, D. L. Rinker and R. Tsao, Ergosterol Profiles, Fatty Acid Composition, and Antioxidant Activities of Button Mushrooms as Affected by Tissue Part and Developmental Stage, J. Agric. Food Chem., 2010, 58, 11616-11625.

15 A. Villares, A. García-Lafuente, E. Guillamón and Á. Ramos, Identification and quantification of ergosterol and phenolic compounds occurring in Tuber spp. truffles, J. Food Compos. Anal., 2012, 26, 177-182.

16 S. H. Hu, C. L. Zeng, C. C. Yi, L. L. Juang, S. C. Ker, Y. L. Min and C. W. Jinn, Antihyperlipidemic and antioxidant effects of extracts from Pleurotus citrinopileatus, J. Agric. Food Chem., 2006, 54, 2103-2110.

17 T. Wu, S. Zivanovic, F. A. Draughon and C. E. Sams, Chitin and chitosan-value-added products from mushroom waste, J. Agric. Food Chem., 2004, 52, 7905-7910.

18 L. Vasylenko, K. Loewe and J. Wegener, Applicability of agricultural by-products from the mushroom industry for fueling, Landtechnik, 2008, 63, 34-35.

19 A. Gil-Ramírez, A. Ruiz-Rodríguez, F. R. Marín, G. Reglero and C. Soler-Rivas, Effect of ergosterol-enriched extracts obtained from Agaricus bisporus on cholesterol absorption using an in vitro digestion model, J. Funct. Foods, 2014, 11, 589-597.

20 S. A. Heleno, P. Diz, M. A. Prieto, L. Barros, A. Rodrigues, M. F. Barreiro and I. C. F. R. Ferreira, Optimization of ultrasound-assisted extraction to obtain mycosterols from Agaricus bisporus L. by response surface methodology and comparison with conventional Soxhlet extraction, Food Chem., 2016, 197, 1054-1063.

21 Aoac, Official methods of analysis of AOAC INTERNATIONAL, Aoac Off. Methods Anal., 2012, 1-21.

22 A. H. P. Souza, R. C. G. Corrêa, L. Barros, R. C. Calhelha, C. Santos-Buelga, R. M. Peralta, A. Bracht, M. Matsushita and I. C. F. R. Ferreira, Phytochemicals and bioactive properties of Ilex paraguariensis: An in-vitro comparative study between the whole plant, leaves and stems, Food Res. Int., 2015, 78, 286-294.

23 S. A. Heleno, L. Barros, M. J. Sousa, A. Martins and I. C. F. R. Ferreira, Study and characterization of selected nutrients in wild mushrooms from Portugal by gas chromatography and high performance liquid chromatography, Microchem. J., 2009, 93, 195-199.

24 S. A. Heleno, L. Barros, M. J. Sousa, A. Martins and I. C. F. R. Ferreira, Tocopherols composition of Portuguese wild mushrooms with antioxidant capacity, Food Chem., 2010, 119, 1443-1450.

25 R. M. V. Abreu, I. C. F. R. Ferreira, R. C. Calhelha, R. T. Lima, M. H. Vasconcelos, F. Adega, R. Chaves and M.-J. R. P. Queiroz, Anti-hepatocellular carcinoma activity using human HepG2 cells and hepatotoxicity of 6-substituted methyl 3-aminothieno 3,2-b pyridine-2carboxylate derivatives: In vitro evaluation, cell cycle analysis and QSAR studies, Eur. J. Med. Chem., 2011, 46, 58005806.

26 J. T. Melchior, J. K. Sawyer, K. L. Kelley, R. Shah, M. D. Wilson, R. R. Hantgan and L. L. Rudel, LDL particle core enrichment in cholesteryl oleate increases proteoglycan binding and promotes atherosclerosis, J. Lipid Res., 2013, 54, 2495-2503.

27 P. J. H. Jones, D. S. MacKay, V. K. Senanayake, S. Pu, D. J. A. Jenkins, P. W. Connelly, B. Lamarche, P. Couture, P. M. Kris-Etherton, S. G. West, X. Liu, J. A. Fleming, R. R. Hantgan and L. L. Rudel, High-oleic canola oil consumption enriches LDL particle cholesteryl oleate content and reduces LDL proteoglycan binding in humans, Atherosclerosis, 2015, 238, 231-238. 